\title{
Thermal Performance Improvement Study of a Solar Collector with Compound Parabolic Concentrator
}

\author{
Md. Forhad Ibne Al Imam, Mohd. Rafiqul Alam Beg and Md. Shamimur Rahman
}

\begin{abstract}
Heating water with solar energy is easy and effective in both domestic and industrial areas. The initial implementation cost of a solar-water-heating system is high but long term use of it makes it cost effective. For geographical location, Bangladesh is very suitable for using it. In a solar collector system, collector area is an important design factor. To achieve better thermal performance, $0.81 \mathrm{~m}^{2}$ solar collector was used in this study. Commonly used flat plate collector takes more space to be installed. In Bangladesh, space on the roofs of houses and industries are limited and so there is a little scope to use flat plate collector system. Compound parabolic collector can solve this problem. Solar collector with compound parabolic collector needs less space than flat plate collector with reflector. When compound parabolic concentrator was attached with the solar collector, thermal performance improves. Compare with other alternatives that improve thermal efficiency, compound parabolic concentrator shows better thermal performance. Compare thermal efficiency of the consecutive three months. In this system, when water flow rate increase, outlet water temperature decrease but thermal efficiency increases. It is also observed that when solar intensity increases, thermal efficiency also increases likewise when solar intensity decreases, thermal efficiency also decreases. In this research, outputs of different similar researches are compared to show the effectiveness of the compound parabolic concentrator based solar collector. The compound parabolic concentrator reflects more solar radiation, eventually directs it to the collector and increased the difference between the inlet and outlet water temperature.
\end{abstract}

Index Terms-Solar Energy; Thermal Performance; Compound Parabolic Concentrator; Thermal Efficiency.

\section{INTRODUCTION}

In the recent years, more resources had been placed into researching for more alternatives to deal with the shortage of natural resources and its depletion. Everyone feared for the day when resources will no longer be available hence the concept of recycling comes into place. Other than that more efforts had been placed into researching for new ways of harnessing energy, allowing us to reduce the rate at which resources depleted. Energy includes one powerful and reliable source which is our sun, constantly providing us with energy that is clean, renewable and free [1]. The flat plate solar collector with and without ETFE foil between cover glass and absorber was designed and tested by Ziqian

Published on November 30, 2018.

F. I. Al Imam is with the Department of Mechanical Engineering, Rajshahi University of Engineering \& Technology, Rajshahi 6204, Bangladesh (e-mail: forhadibne@ gmail.com).

R. A. Beg is with the Department of Mechanical Engineering, Rajshahi University of Engineering \& Technology, Rajshahi 6204, Bangladesh.

S. Rahman is with the Department of Glass and Ceramic Engineering, Rajshahi University of Engineering \& Technology, Rajshahi 6204, Bangladesh.
Chen et al. The efficiency of the solar collector with ETFE foil was $10 \%$ higher compare with ETFE foil. It was noted that fluid flow rate of the collector was increased, the heat loss coefficient was decreased and the start efficiency and efficiency were also increased [2]. Tripanagnostopoulous et al. made and investigated solar collector with glazing and without glazing system for water heating system. It is noted that when use flat booster reflector, thermal output energy increase and improving their performance [3]. The analytical model for solar thermal systems with experimental validation was developed by E. Bellos and C. Tzivanidis. He predicted that this model is very useful for accurate and quick calculations on solar thermal systems for optimize [4]. Soteris A. Kalogirou is investigated the various applications of solar thermal collectors. He also discussed show to the reader the spread of its compatibility. It covers solar water heating, which comprise direct and indirect systems and air system, integrated collector storage, thermosyphon. He also provides significant benefits and should be used whenever possible. He again investigated the environmental problems related to the use of conventional source of energy and benefits by renewable energy system [5]. Another experimental analysis has been developed and used to determine the performance of a novel solar water heating system and the system performance have been measured and compared. The result shown that this system is more effective for application of solar energy [6] A. Ibrahim et al. was reviewed different types of solar collector and examine parameters of the design, performance evaluation of water, air and combination of air and water based collector. It was noted that flat plate solar collector provides low energy application in industrial and residential area [7]. The incident radiation value was different and its best value was about $1100 \mathrm{~W} / \mathrm{m}^{2}$. The solar collector has low and variable radiation problem. For flat plate system, moderate temperature is gained [8]. Hot water is used in domestic applications and industrial processes. Heat comes from transformation of solar energy and the system uses various conventional collectors with glass cover and metal absorber plate [9].

In this work, Thermal performance of the water collector was observed after using CPC and compared to the conventional system. The thermal performance of solar water collector is evaluated from the basic derivation of Hottel-Bliss-Whillier equation. Better thermal performance was selected after comparing the results of three consecutive months i.e. March, April and May. 


\section{EXPERIMENTAL SETUP AND TEST PROCEDURE}

\section{A. Materials and methods}

For carrying out the experiment, the system is made of a compound parabolic concentrator, a thermal solar collector and a connecting pipe. The compound parabolic concentrator normally consists of two mercury coated reflective pieces of glass mounted on top sides of the system. In this experiment, copper tubes of $6.2 \mathrm{~m}$ length and $2.54 \mathrm{~cm}$ diameter are used. These pipes placed $7.55 \mathrm{~cm}$ away from one another and they bend U-shape at both ends as shown in Fig. 1. The top surface of the collector is then covered with $3 \mathrm{~mm}$ thick flat transparent glass which has higher transmission of solar radiation and $4 \mathrm{~cm}$ space between single glass cover and absorber plate was used in this experiment.

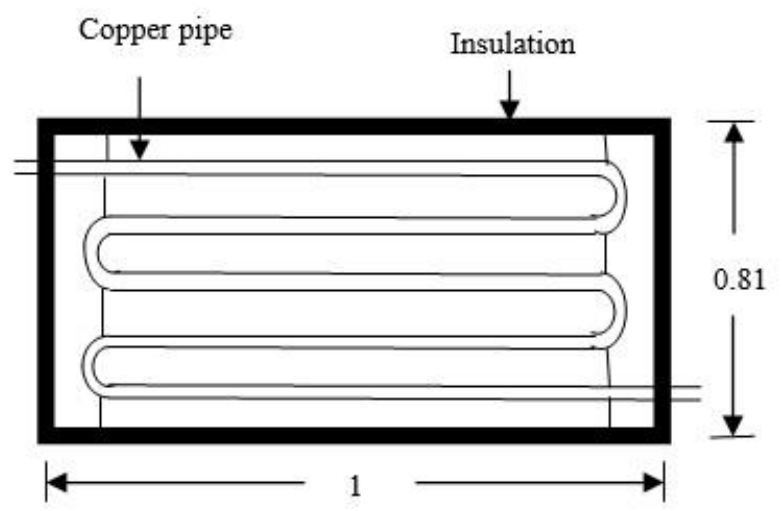

Fig. 1. Sectional view of a solar collector.

The thermal solar collector box was made of GI sheet and its dimension is $0.81 \mathrm{~m}$ by $1 \mathrm{~m}$. The inlet pipe of the collector carries normal water of ambient temperature to the system and the outlet pipe supply hot water from the system. The design of the collector ensures that fluid can flow at a constant flow rate through the collector. The CPC is placed in a way that helps to collect highest solar radiation in the expected seasons. The dimension of the CPC has $1.66 \mathrm{~m}$ heat to head reflector distance. The height of CPC has 1.89 $\mathrm{m}$ from top to bottom as shown in Fig. 2.

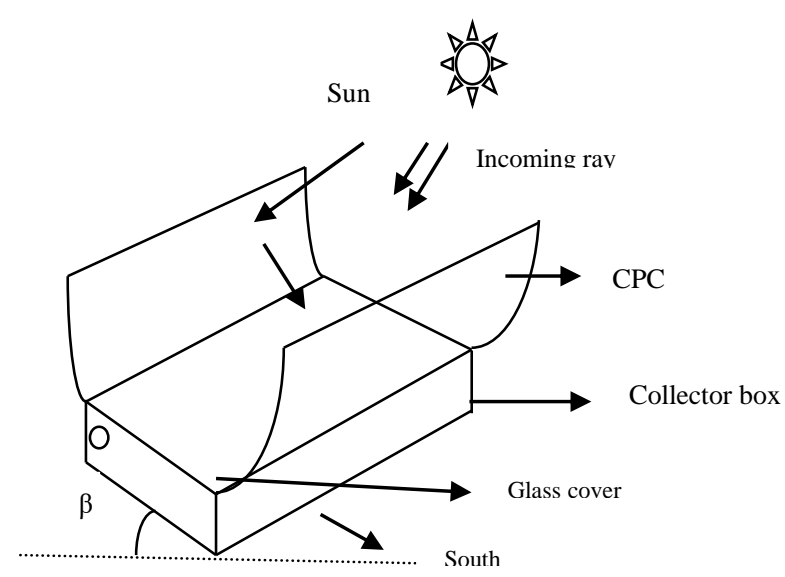

Fig. 2. Thermal solar collector system used in this study

The best stationery was orientated in the south face. For maximum performance all the year round, the inclination of the whole system to the horizontal plane is kept between 100 to 200 more towards south than the actual geographical latitude of the area. The system was implemented is Rajshahi (Latitude 24.00oN), Bangladesh and the tilt angle of 450 was kept to match the latitude. The absorber plate joins at middle of the pipe. The absorber plate and the copper the pipes absorb the radiation of the sun. The solar collector uses an absorber plate made of pure copper and absorbs the higher amount of incident radiation. The heated water is then carried through the copper tube. The natural convection process helps the water to rise through the tubes and then the heated water goes to the storage tank. The corkwood was used to minimize heat loss by conduction through radiation. The thickness used to insulate the box was $5 \mathrm{~cm}$. The experimental setup is installed on roof top of heat engine lab in RUET.

\section{B. Measuring equipment}

Solar radiation intensity was measured every half an hour with pyranometer, with the accuracy of $\pm 10 \mathrm{~W} / \mathrm{m}^{2}$. Different data collected during the day were continuously monitored in the period from 10:30 a.m. to 4 p.m. The outlet water and inlet water temperature from the collector were measure by thermometer with a accuracy of $\pm 0.5^{\circ} \mathrm{C}$, while the flow meter was used for measurement of the water mass flow, and was selected as $0.002 \mathrm{Kg} / \mathrm{s}$ and $0.004 \mathrm{Kg} / \mathrm{s}$ with the accuracy of $\pm 4 \%$. For the measurement of plate temperature, six thermocouples were placed at different positions on the plate along the flow direction, with the accuracy of $\pm 0.5^{\circ} \mathrm{C}$. The glass temperature was measured by the digital surface temperature sensor with accuracy of $\pm 1^{\circ} \mathrm{C}$.

\section{MATHEMATICAL ANALYSIS}

The thermal network for a water collector system is shown in Fig. 4. The amount of solar energy $\mathrm{S}$ is received by the absorber plate and express plate temperature is $T_{p}$. This energy is distributed to losses and to useful energy gain. The loss energy passed through bottom side, edges side and top side.

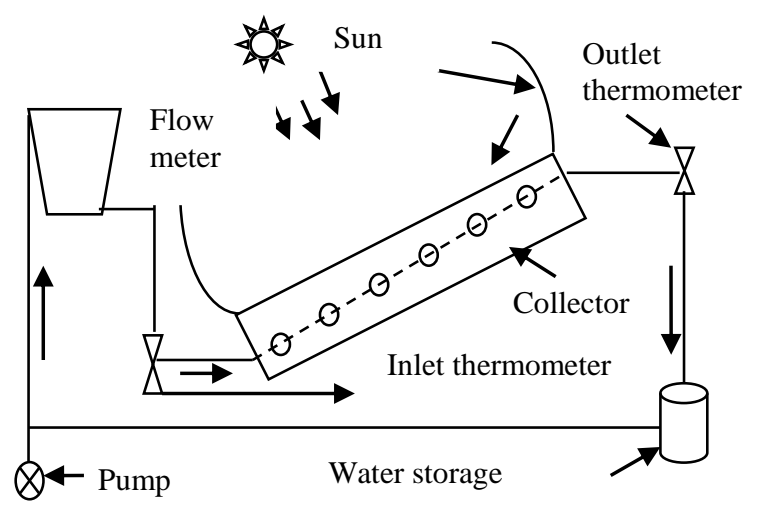

Fig. 3. Schematic diagram of the thermal collector system

The overall loss coefficient $\left(\mathrm{U}_{L}\right)$ is given by:

$$
U_{L}=U_{t}+U_{b}+U_{e}
$$

Where, $U_{t}$ is top heat loss of the collector, $U_{b}$ is bottom heat loss of the collector and $U_{e}$ is side heat loss of the collector.

Top heat loss coefficient of the system is given by: 


$$
\left.U_{t}=\frac{1}{h_{w+h_{r, c-s}}}+\frac{1}{h p-c+h_{r, p-c}}\right]^{-1}
$$

Where $h_{w}$ is wind velocity of convection, $h_{r, c-s}$ is radiation heat transfer coefficient from cover to sky, $h_{p-c}$ is convection heat transfer coefficient from pipe to cover and $h_{r, p-c}$ is radiation heat transfer coefficient from cover to sky.

Bottom heat loss coefficient $\left(U_{b}\right)$ is given by:

$$
U_{b}=U_{e}=\frac{K}{x}
$$

Where, $\mathrm{x}$ is the thickness of the insulation and $\mathrm{K}$ is the insulation thermal conductivity [10].

Useful energy gain of this collector system is given by:

$$
Q_{u}=F_{R} A_{c}\left[\mathrm{~S}-U_{L}\left(T_{i}-T_{a}\right]\right.
$$

Useful energy of working water is expressed from:

$$
\mathrm{Q}_{\mathrm{w}}=\mathrm{m} C_{p}\left(T_{0}-T_{i}\right)
$$

The thermal efficiency of the collector system is calculated from:

$$
\eta_{t}=\frac{Q_{U}}{H A_{c} \eta_{0 C R}}
$$

Where, $\mathrm{H}$ is the total solar radiation on the collector, $\mathrm{CR}$ is the concentration ratio and $\eta_{0}$ is the optical efficiency [11].

\section{RESULTS AND OBSERVATIONS}

Normal domestic supply water with ambient temperature was used in the system between March 2016 to May 2016.

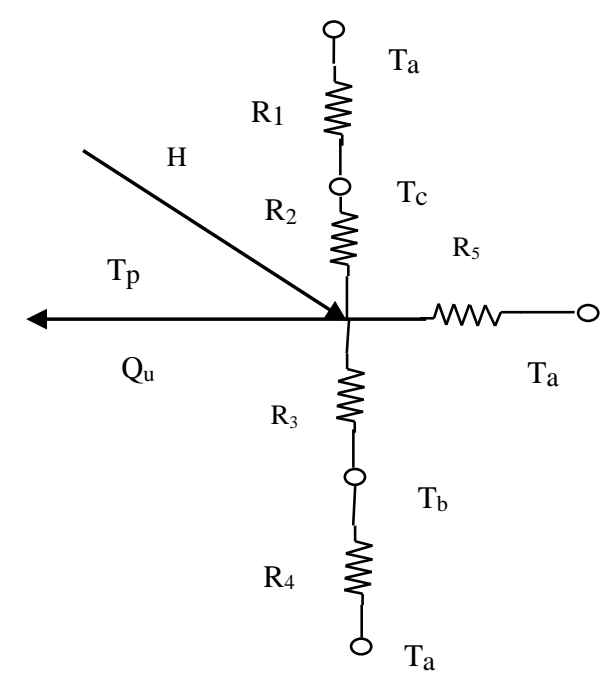

Fig. 4. Thermal network for collector system

The experimental result was collected at intervals of one hour between 10.30 a.m. to 4 p.m. The water inlet and outlet temperature was measured using digital thermometer. The absorber plate temperature of the system was measured by thermocouples which distributed at various positions on the surface of the collector. The glass cover temperature was measured by heat sensor in which laser light fell on the glass surface and got direct reading and the ambient temperature was measure by thermocouple. Water heating type CPC solar collector with copper absorber plate and single glass cover was tested under the outdoor conditions. Data such as absorber plate temperature, inlet water temperature, outlet water temperature, ambient temperature and glass cover temperature regarding the collector were found. The difference between outlet and inlet temperatures is proportional to thermal efficiency. This theory is used to improve thermal performance. Difference between outlet and inlet temperatures depends on solar radiation. If solar intensity increases, outlet temperature also increases. Solar intensity remains fixed for a particular geographical area because it is not possible to increase the intensity of solar radiation falling on a particular geographical area.

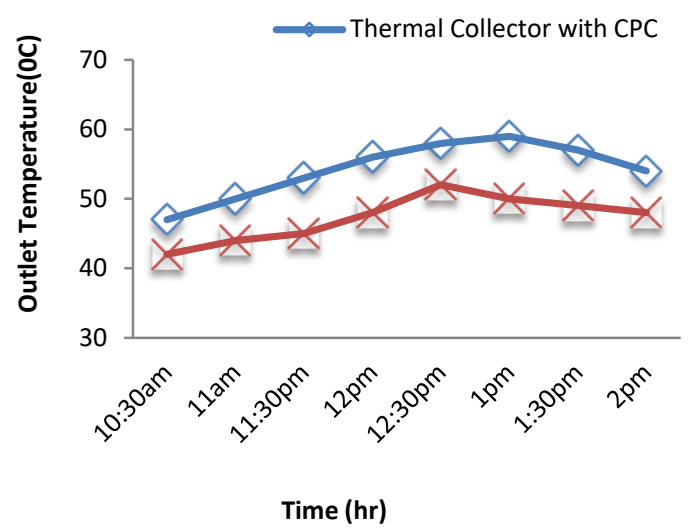

Fig. 5. Change of outlet temperature of water with day time on $5^{\text {th }}$ May 2016.

Here CPC is placed between the incoming solar radiation and the water collector. The rays from the sun fall on the collector after being reflected by CPC. As a result, the difference between outlet and inlet temperature increase. In the Fig. 5, change of outlet temperature on a clear sunny day ( $5^{\text {th }}$ May 2016) is shown. Data were collected every half an hour. At 1p.m maximum temperature of $58^{\circ} \mathrm{C}$ was found. Increase of temperature was smooth from 10:30 a.m. to 1 p.m. Outlet temperature was the highest at 1 p.m. as the solar intensity was the also the highest of value of 980 $\mathrm{W} / \mathrm{m}^{2}$. In this type of collectors, some rays of the sun directly fall on the solar collector and some rays fall on the collector after reflected by the CPC, which increases the outlet temperature. The Fig. 6 shows that as the duration of solar time increases, thermal efficiency also increases. Maximum thermal efficiency of value $60 \%$ was gain at 1 p.m. this figure also shows a comparison between the data of this study and that of H. Bhowmik, which shows similar thermal efficiency [12]. 


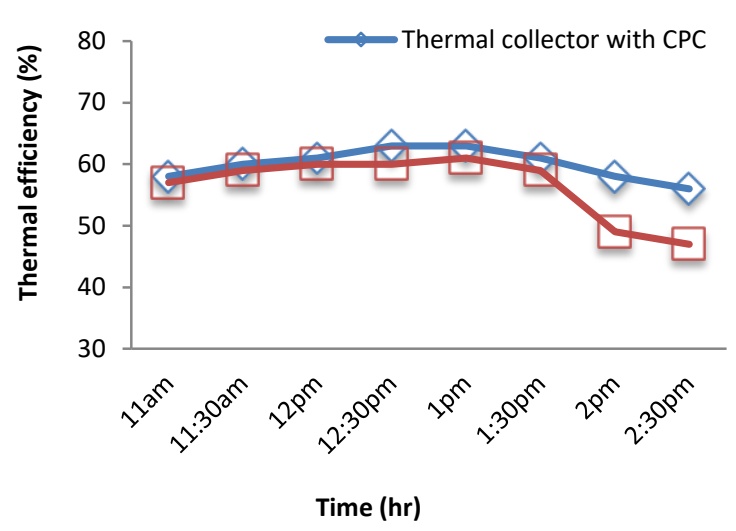

Fig. 6. Change of thermal efficiency with day time.

But this new design provides more thermal efficiency. From this comparison, it can be said that this design is more efficient than the previous design. Fig. 7, shows the change of outlet temperature as the duration of solar time increases. In this figure, a comparison is made between the date of $7^{\text {th }}$ May 2016 for the flow rate of $0.004 \mathrm{Kg} / \mathrm{s}$ and those of $8^{\text {th }}$ May 2016 for the flow rate of $0.002 \mathrm{Kg} / \mathrm{s}$. the outlet temperature increase remains similar for the two types of water flow rate. The figure also shows that if the water flow rate remains constant at $0.004 \mathrm{Kg} / \mathrm{s}$, maximum outlet temperature of value $58^{\circ} \mathrm{C}$ is gained at 1 p.m. It also shows that if water flow rate increases outlet temperature falls because water takes time to absorb heat as the water flow rate increases.

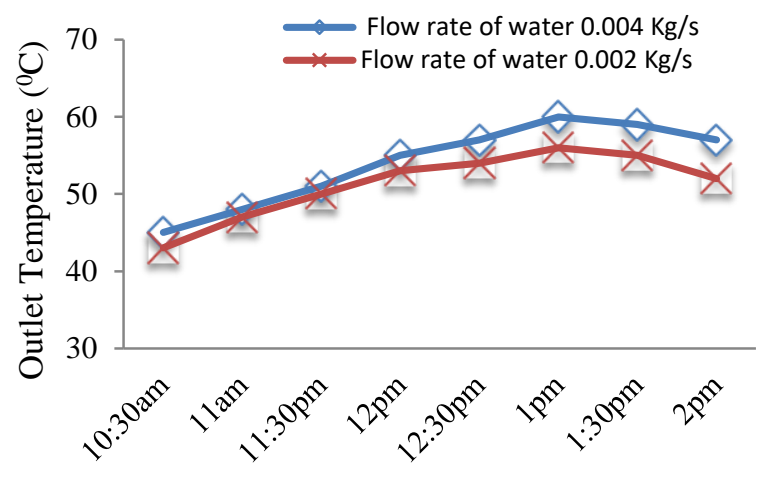

Time (hr)

Fig. 7. The change of outlet temperature of water with day time on $7^{\text {th }}$ May and $8^{\text {th }}$ May 2016.

In the Fig. 8, maximum thermal efficiency of $60 \%$ and $56 \%$ were gained for the respective water flow rates of $0.004 \mathrm{Kg} / \mathrm{S}$ and $0.002 \mathrm{Kg} / \mathrm{s}$. the research of A. fudhoi also shows similar result. From this result, we see that as the flow rate of water increases, thermal efficiency also increases [13]. The Fig. 9 shows the change of outlet temperature in March, April and May. It shows the increase in temperature from 11 a.m. to 1 p.m. Maximum outlet temperature of $50-58^{\circ} \mathrm{C}$ was gained at 1 p.m. From 2 p.m. to 4 p.m. outlet temperature was $46^{\circ} \mathrm{C}$ to $55^{\circ} \mathrm{C}$. In May outlet temperature was maximum as the solar intensity was the highest. In March and April outlet temperature remained between $42^{\circ} \mathrm{C}$ to $51^{\circ} \mathrm{C}$.

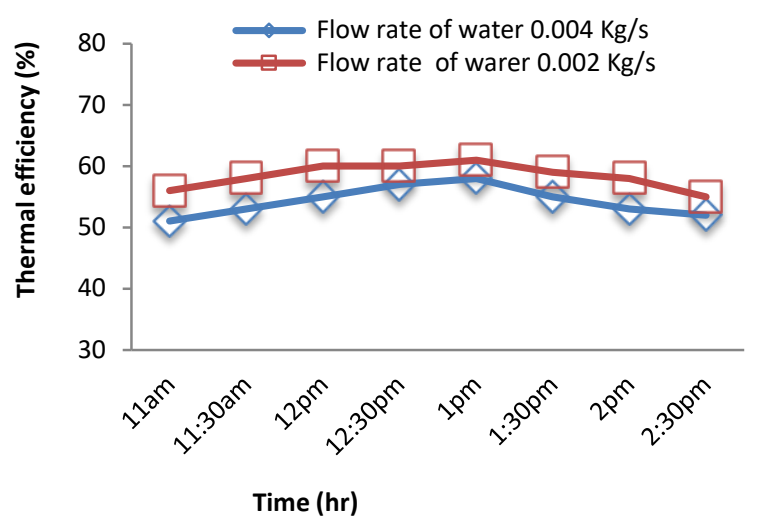

Fig. 8. The variation of thermal efficiency at different flow rate.

The graph illustrates comparison the outlet water temperature for the month of March, April and May. This was based on the experimental study. The upper line represents hourly water outlet temperature of May while the middle and lower line represents outlet water temperature of April and March respectively. According to the graph, the outlet temperature of May will increase more quickly than other two months because intensity of solar radiation was higher. The Fig. 10 shows the change of thermal efficiency in March, April and May. The figure shows thermal efficiency remained similar from 11a.m. to 4 p.m. In March maximum thermal efficiency was $52 \%$, in April it was $55 \%$ and in May it was $60 \%$. A comparison between flat plate collector and flat plate collector with compound parabolic collector was made in the paper published by $\mathrm{S}$. Sobhansarbandi, that shows that CPC system takes less space than the basic flat plate system [14].

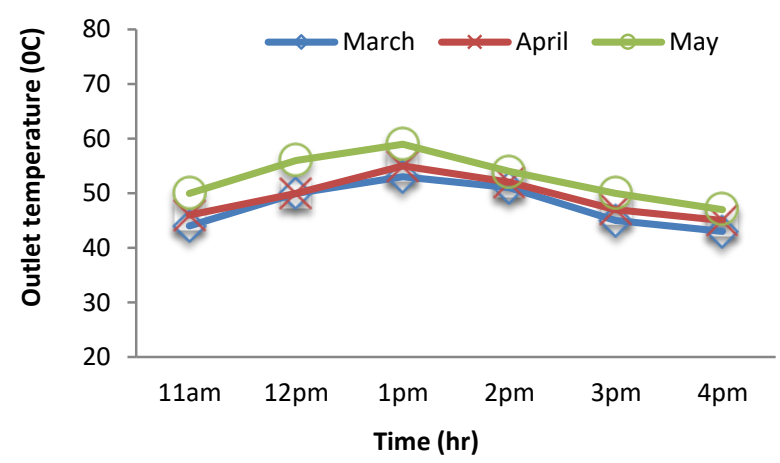

Fig. 9. Changes in outlet temperature with time for month of March, April and May.

It showed that basic flat plate system needs $8 \mathrm{~m}^{2}$ to give the same output of $2 \mathrm{~m}^{2} \mathrm{CPC}$ system. In our study we see similar performance. In a paper published by J. Sankar water and $\mathrm{CO}_{2}$ were used to see the thermal performance of the system [15]. It was observed that when surface area increases, thermal efficiency drops as heat loss increases. $18 \%$ performance improves if $\mathrm{CO}_{2}$ is used instead of water as heat transfer fluid. In this way, maximum temperature around $50-60^{\circ} \mathrm{C}$ was achieved. In comparison, CPC-based solar collector gives better output. We found the maximum output temperature of $58^{\circ} \mathrm{C}$ in our study. 


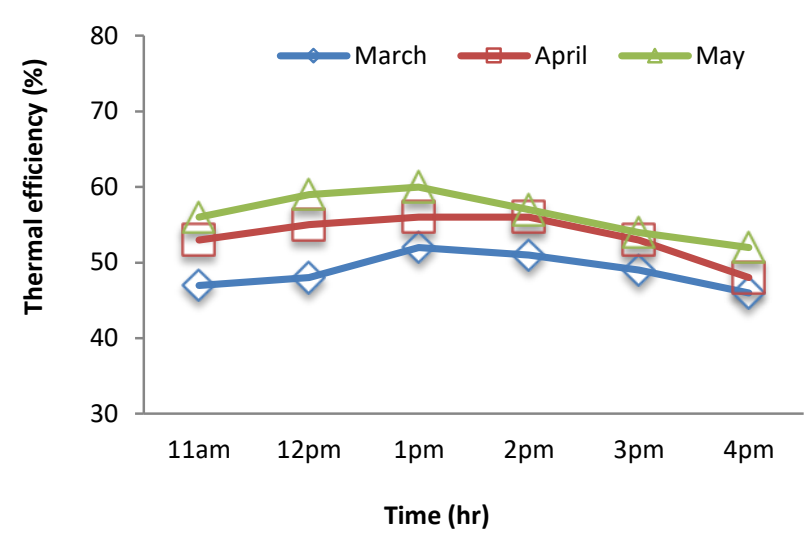

Fig. 10. Changes in thermal efficiency with time for month of March, April and May.

Hence we can conclude that solar collector with compound parabolic concentrator takes less space to be installed and provides desired thermal efficiency. This newly designed compact water collector has higher solar thermal efficiency than the previous models used by other researchers. Performance is tested which shows a better result which is compared with the results of other solar collector models designed by different previous researchers. This research is highly informative, which will be very useful to future researchers who are interested in utilizing solar energy.

\section{CONCLUSION}

Thermal efficiency depends on solar radiation. The maximum thermal efficiency of $60 \%$ was gained at 1 p.m. It seems that outlet temperature was increase up to 1 p.m. and the maximum outlet temperature $58^{\circ} \mathrm{C}$ for month of May. In this new system most of the solar radiation directly falls on the collector and some fall indirectly after being reflected by the CPC, which improves the thermal performance of the collector. CPC helps to gain maximum output temperature as it boosts thermal efficiency by directing more solar radiation to the collector through reflection. As solar intensity increases, temperature in all areas of the collector increases. Outlet temperature of the water starts to fall as the solar intensity decreases. Water flow rate is adjusted depending on solar intensity to increase the outlet water temperature and thermal efficiency. It can be highlighted that the best water flow rate was $0.004 \mathrm{Kg} / \mathrm{s}$ because it gives maximum thermal efficiency. It shows that thermal efficiency in May was better than those of March and April. It is concluded that outlet temperature and thermal efficiency are compared to show the most effective way of operating the system.

\section{REFERENCES}

[1] K. H. Solangi, M. R. Islam, R. Saidur, N. A. Rahim, and H. Fayaz, "A review on global solar energy policy," Renewable and Sustainable energy reviews, vol. 15, pp. 2149- 2163, 2011.

[2] Z. Chen, S. Furbo, B. Perers, J. Fan and E. Andersen, "Efficiencies of flat plate solar collectors at different flow rates," Energy Procedia, vol. 30, pp. 65-72, 2012.

[3] Y. Tripanagnostopoulos, M. Souliotis and T. H. Nousia, "Solar collectors with colored absorbers," Solar energy, vol. 68, pp. 343356, 2000.

[4] E. Bellos, and C. Tzivanidis, "Development of an analytical model for the daily performance of solar thermal systems with experimental validation," Sustainable Energy Technologies and Assessments, vol. 28, pp. 22-29, 2018.

[5] A. Soteris and Kalogirou, "Solar thermal collectors and applications," Progress in energy and combustion science, vol. 30, pp. 231-295, 2004.

[6] W. Wua, S. Daib, Z. Liua, Y. Douc, J. Huaa, M. Lia, X. Wanga and $\mathrm{X}$. Wanga, "Experimental study on the performance of a novel solar water heating system with and without PCM," Solar Energy, vol. 171, pp. 604-612, 2018.

[7] A. Ibrahim, M. Y. Othman, M. H. Ruslan, S. mat and K. sopian, "Recent advances in flat plate photovoltaic/thermal solar collectors," Renewable and sustainable energy Reviews, vol. 15, pp. 352-365, 2011.

[8] S. O. Enibe, "Thermal analysis of a natural circulation solar air heater with phase change material energy storage," Renewable Energy, vol 28, pp. 2269-2299, 2003.

[9] N. M. Nahar, "Year round performance and potential of a natural circulation type of solar water heater in India," Energy and Buildings, vol. 35 pp. 239-247, 2003.

[10] S. A. Kalogirou, "Solar thermal collectors and applications," Progress in energy and combustion science, vol. 30, pp. 131-295, 2004.

[11] J. A. Duffie and W. A. Beckman, Solar Energy of Thermal Processes; New York: John Wiley and Sons Inc, 2006.

[12] H. Bhowmik and R. Amin, "Efficiency improvement of flat plate solar collector using reflector," Energy Reports, vol. 3, pp. 119-123, 2017.

[13] A. Fudholi, K. Sopian, M. H. Yazdi and M. H. Ruslan, "Performance analysis of photovoltaic thermal water collectors," Energy conversion and Management, vol. 78, pp. 641-651, 2014.

[14] S. Sobhansarbandi and U. Atikol, "Performance of Flat-Plate and Compound Parabolic Concentrating Solar Collectors in Underfloor Heating Systems," Journal of Solar Energy Engineering, vol. 137 / 034501, 2015.

[15] J. Sarkar, "Performance of a flat plate solar thermal collector using supercritical carbon dioxide as heat transfer fluid," International Journal of Sustainable Energy, vol. 32, no. 6, pp. 531-543, 2013.

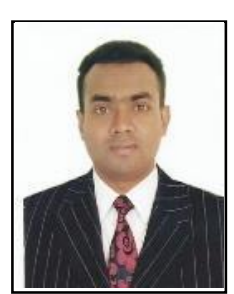

Md. Forhad Ibne Al Imam was born in Pabna, Bangladesh. He was graduated with B.Sc and M.Sc in Mechanical Engineering degree from Rajshahi University of Engineering \& Technology, Bangladesh. Currently, he is a Ph.D candidate at the same university. He has been working as an Assistant Professor (Mechanical) at Textile Engineering College, Bangladesh. His research interests include solar energy, alternative fuel and material science. 